\title{
The association of celebrity worship with problematic Internet use, maladaptive daydreaming, and desire for fame
}

\author{
ÁGNES ZSILA ${ }^{1,2 *}$, LYNN E. MCCUTCHEON ${ }^{3}$ and ZSOLT DEMETROVICS ${ }^{1}$ \\ ${ }^{1}$ Institute of Psychology, ELTE Eötvös Loránd University, Budapest, Hungary \\ ${ }^{2}$ Doctoral School of Psychology, ELTE Eötvös Loránd University, Budapest, Hungary \\ ${ }^{3}$ North American Journal of Psychology, Winter Garden, FL, USA
}

(Received: April 29, 2018; revised manuscript received: June 14, 2018; accepted: July 7, 2018)

\begin{abstract}
Background and aims: Celebrity worship, defined as an obsessive fascination with a famous person, has been associated with several mental health problems, such as symptoms of depression and anxiety, dissociation, and body image concerns. The aim of this study was to extend the scope of investigation of previous research on psychological correlates by exploring the association of celebrity worship with compulsive behaviors, such as problematic Internet use, maladaptive daydreaming, desire for fame, and self-efficacy. Methods: A voluntary sample of 437 Hungarian adolescents and adults $\left(78.3 \%\right.$ male; $M_{\text {age }}=24.7$ years, $\left.S D=7.4\right)$ completed an online questionnaire focusing on attitudes toward celebrities and other relevant variables. Results: As a result of hierarchical regression analyses, high levels of celebrity worship were associated with problematic Internet use, maladaptive daydreaming, and desire for fame. Furthermore, females were at higher risk to become obsessed with celebrities than males. Discussion and conclusion: These findings provide with a more comprehensive picture of psychological difficulties associated with celebrity worship and may contribute to a better understanding of this phenomenon.
\end{abstract}

Keywords: celebrity worship, compulsive behaviors, desire for fame, maladaptive daydreaming, problematic Internet use, self-efficacy

\section{INTRODUCTION}

Since the early 2000s, there has been an increasing research interest in individuals who are passionately devoted to celebrities (Sansone \& Sansone, 2014). Enthusiasm toward a famous person can be perceived as a continuum, ranging from healthy appreciation to an obsessive preoccupation with a celebrity that could interfere with several life aspects of a person (e.g., work- or education-related performance and interpersonal relationships; Maltby, Houran, \& McCutcheon, 2003; McCutcheon, Lange, \& Houran, 2002; McCutcheon, Maltby, Houran, \& Ashe, 2004; Sansone \& Sansone, 2014). Obsessive fascination with a celebrity, conceptualized as celebrity worship (McCutcheon et al., 2002), can be manifested in various psychological features (Sansone \& Sansone, 2014).

McCutcheon et al. (2002) defined three dimensions of celebrity worship. First, entertainment-social dimension (i.e., low level of celebrity worship) reflects a healthy motivation of reading, listening, or viewing the works of an admired celebrity, seeking information about his/her career, and sharing this enthusiasm with friends or family members (Griffith, Aruguete, Edman, Green, \& McCutcheon, 2013; McCutcheon et al., 2002). This dimension has been linked to extraversion (Maltby et al., 2003, 2004). Second, intense-personal dimension (i.e., moderate level of celebrity worship) represents intense and compulsive feelings toward one's favorite celebrity (e.g., loss of control over recurring thoughts about a celebrity) (McCutcheon, Aruguete, Jenkins, McCarley, \& Yockey, 2016; McCutcheon et al., 2002). This dimension has been associated with neuroticism (Maltby et al., 2003), symptoms of depression and anxiety (Maltby, McCutcheon, Ashe, \& Houran, 2001), somatic symptoms (Maltby et al., 2004), poor-quality relationships (McCutcheon, Gillen, Browne, Murtagh, \& Collisson, 2016), and concerns about body image (Maltby \& Day, 2011; Swami, Taylor, \& Carvalho, 2009). Third, borderline-pathological dimension reflects extreme attitudes and behaviors toward a celebrity that are considered as maladaptive forms of admiration (e.g., if one's favorite celebrity asked the person to do something illegal as a favor, he/she would do it; McCutcheon, Aruguete, Jenkins, et al., 2016; McCutcheon et al., 2002). This dimension has been related to narcissism (Ashe, Maltby, \& McCutcheon, 2005), psychoticism (Maltby et al., 2003, 2004), and tendencies toward criminal behaviors and addiction (Sheridan, North, Maltby, \& Gillett, 2007).

Although several studies have explored the psychological well-being of individuals expressing high levels of celebrity worship (e.g., Maltby, Day, McCutcheon, Houran, * Corresponding author: Ágnes Zsila; Institute of Psychology, ELTE
Eötvös Loránd University, 1064 Budapest, Izabella utca 46,
Hungary; Phone: +36 70597 4026; E-mail: zsila.agnes@ppk.elte.hu

This is an open-access article distributed under the terms of the Creative Commons Attribution-NonCommercial 4.0 International License, which permits unrestricted use, distribution, and reproduction in any medium for non-commercial purposes, provided the original author and source are credited, a link to the CC License is provided, and changes - if any - are indicated. 
\& Ashe, 2006; Maltby et al., 2003, 2001), prevalence rates for celebrity worshippers are still unknown (Maltby et al., 2003; Stever, 2011) due to the lack of cutoff scores in the assessment (Stever, 2011) and the convenience samples used in these studies comprising a limited number of participants (generally between 100 and 300 participants) (McCutcheon et al., 2004). Stever (2011) attempted to identify celebrity worshippers based upon middle-scores in the assessment, considering celebrity worshippers who mostly agree with the majority of items of the assessment instrument, whereas non-celebrity worshippers were considered to be those who disagree with most of the items. Across two samples of particularly dedicated Star Trek and Josh Groban fans, Stever (2011) found that $15 \%$ and $58 \%$ of participants could be considered as celebrity worshippers. However, the sample sizes were again very limited (the number of participants were 87 and 105 across the two samples, respectively). In another study by Maltby and Day (2011), 2.5\% and 8\% of young participants (aged between 18 and 23 years) yielded high scores on the two problematic dimensions of celebrity worship (i.e., intense-personal and borderline-pathological), using the same method for evaluation as Stever (2011). Furthermore, Maltby et al. (2003) reported that $36 \%$ of college students and adult participants yielded high scores in general celebrity worship and $27 \%$ in the two problematic dimensions.

Despite the shortcomings of methodology, a considerable number of studies clearly indicate that individuals exhibiting high levels of celebrity worship are more likely to experience severe psychological difficulties (e.g., symptoms of depression and anxiety, somatic symptoms, obsessive-compulsive disorder, and dissociation) than those without a tendency to worship celebrities (Maltby et al., 2001, 2003, 2006). These studies also point out the social aspects of this problem as celebrity worship is generally linked with difficulties in several life aspects (e.g., work and/or studies and social life) (see Sansone \& Sansone, 2014 for a review). Therefore, recent studies investigating this phenomenon still focus on the exploration of psychological correlates of celebrity worship in order to gain a better understanding of the concept of celebrity worship, which can allow for a more rigorous differentiation between an enthusiastic fan and a devoted celebrity worshipper (Stever, 2011).

Despite the prominent role of media in exacerbating fascination with celebrities (Giles \& Maltby, 2004; Martin, McCutcheon, \& Cayanus, 2015), relatively little research attention has been paid to the media use of celebrity worshippers. A recent study by Martin et al. (2015) found a canonical correlation between the three dimensions of celebrity worship and television-viewing motives. In a similar vein, Reeves, Lemons, Clements, Gountas, and Gountas (2013) found strong relationship between celebrity worship and social media use. Based on these findings, this study endeavors to investigate the association between celebrity worship and Internet use habits.

Similar to celebrity worship, problematic Internet use can also be associated with a number of psychological problems that have a negative impact on everyday functioning (e.g., symptoms of depression and anxiety, low levels of subjective well-being, and deteriorated interpersonal relationships) (see Anderson, Steen, \& Stavropoulos, 2017 for a review). Beside problematic Internet use (Király et al., 2014; Shapira, Goldsmith, Keck, Khosla, \& McElroy, 2000), several terms have emerged in the literature to conceptualize this behavior such as "Internet addiction" (e.g., Bai, Lin, \& Chen, 2001; Young, 1998), "pathological Internet use" (Davis, 2001; Niemz, Griffiths, \& Banyard, 2005), or "Internet dependency" (e.g., Lu, 2008; Sun, Rubin, \& Haridakis, 2008). Young (1998) constructed a brief, eight-question assessment instrument that assesses addictive Internet use comprehensively based on the DSM-IV criteria for pathological gambling, including symptoms of preoccupation, the need for using the Internet with increasing amounts of time to gain the same levels of satisfaction, unsuccessful efforts to reduce excessive Internet use, irritability when cutting down the activity, using the Internet longer than intended, risking the maintenance of work- and/or school-related performance and social relationships, lying about the time spent on the Internet, and using the Internet as a coping strategy to escape from real-life problems. Young (1998) proposed that five out of eight criteria should be met to consider an individual being addicted to the Internet. However, researchers argued that Internet use has become an integral part of our lives, resulting in that some aspects of problematic use (e.g., prolonged use of the Internet) may not be associated with decreased levels of well-being (Demetrovics \& Király, 2016; Yellowlees \& Marks, 2007). There has been a debate surrounding the conceptualization and criteria of Internet addition (e.g., whether this behavior should be considered a separate disorder; Griffiths, 2000), resulting in which "problematic Internet use" and "excessive Internet use" have become commonly used terms to describe this behavior (Demetrovics, Szeredi, \& Rózsa, 2008). Problematic Internet use is defined as an inability to control the use of the Internet, which can manifest in psychological distress and impairment in everyday functioning (Shapira et al., 2000).

A commonly held assumption is that problematic Internet use is best predicted by the time spent online; however, empirical findings have not supported this consideration (Caplan, 2002; Davis, Flett, \& Besser, 2002; Demetrovics et al., 2008). Indeed, early theories postulated that heavy use of the Internet is a strong predictor of problematic use; however, empirical research found evidence that heavy use has a weak association with symptoms of problematic Internet use and comorbid disorders (Demetrovics \& Király, 2016). Similar association has been found in relation to video gaming (Király, Tóth, Urbán, Demetrovics, \& Maraz, 2017), revealing that psychiatric symptoms have a stronger association with problematic gaming than with the amount of time spent playing. The same pattern was observed in the study by Brunborg et al. (2013) and Skoric, Teo, and Neo (2009) in relation to well-being and academic performance among gamers. These studies pointed out that problematic Internet use is more strongly associated with physical and mental health concerns than with the amount of time spent online. This study investigates both aspects of Internet use in order to enable a more nuanced understanding of the association between celebrity worship and Internet use habits. Based on the literature of problematic Internet use, it may be expected that the amount of time spent online is 
unrelated to celebrity worship, whereas problematic Internet use may be a possible correlate of this construct. Moreover, this study endeavors to provide a more nuanced picture of psychological difficulties associated with celebrity worship by broadening the scope of investigation to maladaptive daydreaming, desire for fame, and selfefficacy.

Maladaptive daydreaming can also be considered as a potential correlate of celebrity worship due to the similarities in the psychological determinants of the two phenomena. More specifically, maladaptive daydreaming refers to an "extensive fantasy activity that replaces human interaction and/or interferes with academic, interpersonal or vocational functioning" (Somer, 2002, p. 199). Indeed, maladaptive daydreamers were more likely to report symptoms of ADHD, obsessive-compulsive disorder, and dissociation (Bigelsen, Lehrfeld, Jopp, \& Somer, 2016). Furthermore, maladaptive daydreaming was associated with fantasy proneness in the study of Bigelsen et al. (2016), which was also positively related to celebrity worship (Maltby et al., 2006; McCutcheon, Aruguete, McCarley, \& Jenkins, 2016). Despite this association, fantasy proneness and maladaptive daydreaming should be considered as two different constructs, as fantasy proneness theoretically reflects deep involvement in fantasy, encompassing out-of-body, religious, and paranormal experiences (Merckelbach, Horselenberg, \& Muris, 2001), while maladaptive daydreaming captures general but compulsive fantasy activity that interferes with several life aspects (Somer, 2002), similar to celebrity worship (Maltby et al., 2003, 2004).

Another possible correlate of celebrity worship could be the desire for fame. Gountas, Gountas, Reeves, and Moran (2012) elaborate that the desire for fame is an extrinsic need that may stand in the way of personal growth, and has a negative impact on physical and mental health. Indeed, desire for fame was negatively associated with selfacceptance and positively with social recognition and materialism (Gountas et al., 2012). Preliminary findings also confirmed a positive relationship between celebrity worship and desire for fame (Reeves et al., 2013).

Numerous studies have demonstrated a positive association between self-efficacy, well-being, and performance in several aspects (e.g., educational and work-related) (see Stajkovic \& Luthans, 1998 for a review). On the contrary, previous findings suggested that celebrity worship could interfere with major life activities (Maltby et al., 2003, 2004). Therefore, it may be plausible that celebrity worshippers have lower levels of self-efficacy.

\section{The aims of the study}

The aim of this study was twofold: (a) to investigate the association of celebrity worship with problematic and nonproblematic Internet use; (b) to expand the scope of investigation of previous studies on the psychological correlates of celebrity worship by exploring its associations with maladaptive daydreaming, desire for fame, and selfefficacy.

To attain these goals, the following hypotheses were proposed based on the literature:
1. Celebrity worship would be positively associated with problematic Internet use but unrelated to the amount of time spent online.

2. Celebrity worship would be positively associated with maladaptive daydreaming and desire for fame and negatively with self-efficacy.

\section{METHODS}

\section{Participants and procedure}

This study was conducted on a convenience sample of Hungarian adolescents and adults that is not representative of the whole Hungarian population. Participants were recruited from a popular Hungarian website dedicated to video games (GameStar.hu) and smaller online groups (comprising 200-2000 members) dedicated to discussion of various mass media (e.g., cartoons and television shows) and interactive media content (e.g., video games and social networking sites). All administrators agreed to cooperate and advertised the call for voluntary participation. Participants were invited to complete an online questionnaire focusing on attitudes toward celebrities. As an incentive, six 20,000 HUF-worth shopping vouchers (about 77 USD) were raffled off among participants.

A total of 437 participants between 14 and 63 years of age $\left(78.3 \%\right.$ male; $M_{\text {age }}=24.7$ years, $\left.S D=7.4\right)$ completed the online questionnaire. Nearly half of the participants completed high school or a technical training (48.3\%), while one quarter $(26.1 \%)$ had primary school certificate or completed less than eight classes, and one quarter completed their education with a college degree or higher (25.6\%). A considerable proportion of participants were students during the data collection (38.4\%), whereas $36.2 \%$ had a full-time or a part-time job, and $21.1 \%$ studied and worked. Only a minority of participants reported not being either a student or a worker $(4.3 \%)$.

\section{Measures}

Data on major demographic characteristics (i.e., gender, age, educational level, current studies, or work experience) were collected.

Information about participants' favorite celebrity. First, participants were asked to name their favorite celebrity. Based on the general definition used by McCutcheon et al. (2004), "celebrity" was defined as a famous living person or one who died during the respondent's lifetime. Second, participants were asked to indicate the primary field of expertise of their favorite celebrity [acting, music, author, artist, video-making (e.g., vlogger and YouTuber), radio/TV presenter, news, science, sports, medicine, modeling, politics, religion, and other]. Finally, participants were asked to indicate how long time they had been fans of their favorite celebrity $(1=$ less than 1 year, $2=1-2$ years, $3=3-5$ years, and $4=$ more than 5 years), and how strongly they feel about this celebrity (ranging from $1=$ very weak to $7=$ very strong).

Celebrity worship. Participants' attitudes toward their favorite celebrity were assessed using the 23 -item version 
of the Celebrity Attitude Scale (CAS), which has demonstrated good psychometric properties across several studies (for a review, see Griffith et al., 2013; McCutcheon et al., 2004). The CAS assesses three dimensions of celebrity worship: Entertainment-Social (10 items; e.g., "I love to talk with others who admire my favorite celebrity"), IntensePersonal (9 items; e.g., "I share with my favorite celebrity a special bond that cannot be described in words"), and Borderline-Pathological [4 items; e.g., "If someone gave me several thousand dollars to do with as I please, I would consider spending it on a personal possession (like a napkin or paper plate) once used by my favorite celebrity"]. Cronbach's $\alpha$ in this study were .87 for the Entertainment-Social subscale, .88 for the Intense-Personal subscale, and .64 for the Borderline-Pathological subscale. Participants were asked to indicate their agreement with each statement on a 5-point Likert scale (ranging from $1=$ strongly disagree to $5=$ strongly agree). Cronbach's $\alpha$ s of the total scale ranged from .84 to .94 in previous studies (McCutcheon et al., 2004). Cronbach's $\alpha$ in this study was .93. Items were translated and back-translated into Hungarian following the protocol by Beaton, Bombardier, Guillemin, and Ferraz (2000). The total score and scale scores were computed by summing the items of the respective subscales.

Internet use. Participants' Internet use habits were assessed by two measures. First, participants were asked to indicate how many hours they used the Internet on an average weekday and weekend day $(1=$ less than $1 \mathrm{hr}$ a day, $2=1-2 \mathrm{hr}$ a day, $3=3-4 \mathrm{hr}$ a day, $4=5-6 \mathrm{hr}$ a day, and $5=$ more than $6 \mathrm{hr}$ a day). This variable was linearized using the middle points of the values and was entered as a continuous variable in the subsequent data analysis.

Problematic Internet use was assessed using the 6-item version of the Problematic Internet Use Questionnaire (PIUQ-SF-6; Demetrovics et al., 2016). Similar to the original 18-item version of the PIUQ (Demetrovics et al., 2008), the PIUQ-SF-6 assesses problematic Internet use on three dimensions: obsession, neglect, and control disorder. Participants were asked to indicate how often they experienced a range of mental health symptoms related to problematic use (six items; e.g., "How often do you feel tense, irritated, or stressed if you cannot use the Internet for as long as you want to?") $(\alpha=.71)$ on a 5-point Likert scale (ranging from $1=$ never to $5=$ always). In accordance with this study's aim, a total score was calculated by summing the items.

Maladaptive daydreaming. Participants' excessive daydreaming experiences were assessed using the 16-item Maladaptive Daydreaming Scale (MDS-16; Somer, SofferDudek, Ross, \& Halpern, 2017). A typical item of the MDS-16 states: "Some people have the experience of their daydreaming interfering with their academic/occupational success or personal achievements. How much does your daydreaming interfere with your academic/occupational success?" Participants rated all items on an 11-point scale anchored at $0 \%$ and $100 \%$, reflecting how often they had these experiences. Higher scores on the MDS-16 reflect higher levels of maladaptive daydreaming. Cronbach's $\alpha$ was .92 in this study. Scale scores were computed by averaging the items.
Desire for fame. Participants' desire for fame was assessed using the 6-item Desire for Fame Scale (Gountas et al., 2012). A typical item of this scale states: "If I were famous, I would be happier." Participants rated each item on a 5-point Likert scale (ranging from $1=$ strongly disagree to $5=$ strongly agree). Higher scores indicate higher levels of desire for fame. Items were translated and back-translated following the protocol of Beaton et al. (2000). Cronbach's $\alpha$ was .89 in this study. Scale scores were computed by averaging the items.

Self-efficacy. General self-efficacy was assessed using the 8-item New General Self-Efficacy Scale (NGSE; Chen, Gully, \& Eden, 2001). Participants rated each statement (e.g., "I will be able to achieve most of the goals that I have set for myself") on a 5-point Likert scale (ranging from $1=$ strongly disagree to $5=$ strongly agree). Higher scores reflect higher levels of perceived self-efficacy. The translation process of the NGSE was in accordance with the protocol described by Beaton et al. (2000). Cronbach's $\alpha$ was .91 in this study. Scale scores were estimated by averaging the items.

\section{Statistical analysis}

Data analysis was performed using SPSS version 22.0 (IBM SPSS Inc., Chicago, IL, USA). Distribution of participants scoring high on the three subscales of the CAS was determined based upon the calculation of theoretical midpoints as indicated in the study by Maltby et al. (2003). More specifically, participants scoring at or above 30 on the Entertainment-Social subscale, 27 or above on the Intense-Personal subscale, and 12 or above on the Borderline-Pathological subscale were considered those yielding high scores.

Hierarchical linear regression analyses were conducted to explore the associations of the three dimensions of celebrity worship (i.e., Entertainment-Social, Intense-Personal, and Borderline-Pathological) with Internet use habits, maladaptive daydreaming, desire for fame, and self-efficacy. Hierarchical regressions allow for the estimation of $R^{2}$ change between multiple models. Therefore, change in the amount of variance explained in a dependent variable between separate blocks of independent variables can be calculated. Multicollinearity has not been observed in the analyses (VIFs were between 1.00 and 1.38 across all tested models) according to the threshold of $<10$ suggested by O'brien (2007).

As a result, the three hierarchical regression analyses revealed very similar associations between the dependent and the independent variables. It may not be surprising, considering that the three dimensions of celebrity worship are not mutually exclusive categories and there may be considerable overlap between them (McCutcheon et al., 2002) as celebrity worship is more of a continuum than a construct of separate but associated dimensions (McCutcheon et al., 2002; Sansone \& Sansone, 2014). For instance, an individual, who is absorbed in his/her favorite celebrity to the extent that he/she would do an illegal act if his/her favorite celebrity asked him/her (i.e., highly agrees with this item of the Borderline-Pathological subscale), is probably more 
likely to feel that he/she shares a special bond with his/her favorite celebrity that cannot be described in words (i.e., highly agrees also with this item of the Intense-Personal subscale), and may also be expected to enjoy being with others who like his/her favorite celebrity (i.e., highly agrees with this item of the Entertainment-Social subscale). Furthermore, the convergent associations of the three dimensions of celebrity worship with compulsive behaviors may indicate that these addictive tendencies are positively associated with the strength of feelings and dedication in all aspects of celebrity worship, irrespective of the quality of absorption (i.e., deep interest, intense feelings, and pathological worship), which makes it reasonable to consider celebrity worship as a global factor in the current assessment (similar to McCutcheon, Aruguete, Griffith, \& Haight, 2012; McCutcheon, Aruguete, Jenkins, et al., 2016; Reyes, Santiago, Domingo, Lichingyao, \& Onglengco, 2016).

Therefore, in accordance with this study's aim (i.e., exploring the association between celebrity worship, problematic Internet use, and other psychological correlates), and considering the result of these preliminary analyses, the total score of the CAS was used as an outcome variable. With regard to the predictor variables, demographic characteristics (i.e., gender and age) were entered in the first block of the hierarchical regression, whereas Internet use variables [i.e., frequency of usage (hours per day) and problematic use] were added to the model in the second block, and psychological correlates (i.e., maladaptive daydreaming, desire for fame, and self-efficacy) were added in the third block.

\section{Ethics}

Before completing the online questionnaire, participants were requested to provide informed consent by ticking a box, if they were over 14 years old and agreed to the terms of participation. For underage participants (those under 18 years of age), parental approval was also required. All participants were informed about the study's aims, and all provided informed consent.

This study was carried out with the approval of the institutional review board of the research team's university, and the standard of ethics adhered to the principles of the Declaration of Helsinki.

\section{RESULTS}

\section{Descriptive statistics}

Descriptive statistics of the study variables are presented in Table 1.

Favorite celebrities named by participants were very much varied. Overall, there were no celebrities mentioned by at least $10 \%$ of participants. The most frequently reported fields of expertise of favorite celebrities were music (31.8\%), acting (25.9\%), and video-making (13.5\%). Nearly half of the sample was a fan for more than 5 years $(44.9 \%)$, whereas $45.3 \%$ were fans for $1-5$ years, and only a small proportion of participants $(9.8 \%)$ were fans for less than a year. Participants expressed a medium-level emotional connectedness to their favorite celebrities on average $(M=3.78, S D=1.68$, ranging between 1 and 7$)$.

Based upon the calculation of theoretical midpoints proposed by Maltby et al. (2003), 29.1\% of participants scored high on at least one subscale of the CAS. More specifically, using overlapping categories, $27.0 \%$ scored high on the Entertainment-Social subscale, $8.5 \%$ on the Intense-Personal subscale, and further $10.5 \%$ on the Borderline-Pathological subscale. Overall, 5.3\% scored high on both of the two problematic subscales (i.e., Intense-Personal and BorderlinePathological) and $13.8 \%$ on either of the two problematic subscales. Furthermore, 5.3\% scored high on all three subscales.

\section{Correlations between variables}

Pearson's correlations between study variables are presented in Table 2.

All three subscales of the CAS alongside with the total score were strongly associated with the strength of feeling toward the favorite celebrity and moderately with compulsive behaviors (i.e., problematic Internet use, maladaptive daydreaming, and desire for fame). Furthermore, the strength of feeling toward the favorite celebrity was weakly associated with these compulsive behaviors. On the contrary, emotional connectedness was unrelated to self-efficacy. The time period of being a fan was only weakly associated with emotional connectedness, and negatively with the desire for fame and problematic Internet use. Neither celebrity worship nor selfefficacy was associated with the time period of being a fan.

With regard to psychological correlates, maladaptive daydreaming was positively associated with problematic Internet use and desire for fame and negatively with selfefficacy. Weak associations were revealed between desire for fame and problematic Internet use and self-efficacy. Similarly, weak association was found between problematic Internet use and the amount of time spent online.

\section{Hierarchical regression predicting celebrity worship}

To explore associations between celebrity worship, problematic Internet use, and psychological correlates, a hierarchical regression analysis was conducted in which celebrity worship (i.e., the total score of the CAS) was treated as an outcome variable, whereas demographic characteristics, Internet use variables, and psychological correlates were treated as predictor variables. The regression model is presented in Table 3.

All three regression models were significant [Hierarchical regression analyses were performed separately for all three subscales of the CAS. Due to severe similarities in patterns across the models tested on the three dimension of celebrity worship, regression analysis using the total score of the CAS as an outcome variable was presented. However, in more details, variables of Model 1 predicting the EntertainmentSocial dimension of celebrity worship represented $5 \%$ of the total variance, Model 2 reflected 13\%, and Model 3 explained $22 \%$ of the total variance. All models were significant $(p<.001)$. In Model 3 , gender $(B=2.08$, 
Table 1. Descriptive statistics of all study variables

\begin{tabular}{|c|c|}
\hline & Participants $(N=437)$ \\
\hline \multicolumn{2}{|l|}{ Favorite celebrity } \\
\hline \multicolumn{2}{|l|}{ Primary field of expertise } \\
\hline Acting $[n(\%)]$ & $113(25.9 \%)$ \\
\hline Music $[n(\%)]$ & $139(31.8 \%)$ \\
\hline Author $[n(\%)]$ & $5(1.1 \%)$ \\
\hline Artist $[n(\%)]$ & $4(0.9 \%)$ \\
\hline Video-making (e.g., vlogger and YouTuber) $[n(\%)]$ & $59(13.5 \%)$ \\
\hline Radio/TV presenter $[n(\%)]$ & $10(2.3 \%)$ \\
\hline News $[n(\%)]$ & $2(0.5 \%)$ \\
\hline Science $[n(\%)]$ & $30(6.9 \%)$ \\
\hline Sports $[n(\%)]$ & $41(9.4 \%)$ \\
\hline Medicine $[n(\%)]$ & $0(0.0 \%)$ \\
\hline Modeling $[n(\%)]$ & $2(0.5 \%)$ \\
\hline Politics $[n(\%)]$ & $3(0.7 \%)$ \\
\hline Religion $[n(\%)]$ & $3(0.7 \%)$ \\
\hline Other $[n(\%)]$ & $26(5.9 \%)$ \\
\hline \multicolumn{2}{|l|}{ Period of time being a fan } \\
\hline Less than 1 year $[n(\%)]$ & $43(9.8 \%)$ \\
\hline $1-2$ years $[n(\%)]$ & $89(20.4 \%)$ \\
\hline $3-5$ years $[n(\%)]$ & $109(24.9 \%)$ \\
\hline More than 5 years $[n(\%)]$ & $196(44.9 \%)$ \\
\hline \multicolumn{2}{|l|}{ Strength of feeling toward the favorite celebrity (range: $1-7$ ) } \\
\hline Mean $(S D)$ & $3.78(1.68)$ \\
\hline \multicolumn{2}{|l|}{ Celebrity worship } \\
\hline CAS Entertainment-Social (range: 10-46) [mean $(S D)]$ & $24.22(8.27)$ \\
\hline CAS Intensive-Personal (range: 9-42) [mean $(S D)]$ & $15.18(6.81)$ \\
\hline CAS Borderline-Pathological (range: 4-19) [mean $(S D)]$ & $6.92(2.98)$ \\
\hline CAS total mean $(S D)$ (range: $23-100)$ [mean $(S D)]$ & $46.32(16.60)$ \\
\hline \multicolumn{2}{|l|}{ Internet use } \\
\hline Hours per day [mean $(S D)]$ & $4.04(1.68)$ \\
\hline PIUQ-SF-6 Problematic use (range: 6-28) [mean $(S D)]$ & $10.86(3.61)$ \\
\hline \multicolumn{2}{|l|}{ Psychological correlates } \\
\hline MDS-16 maladaptive daydreaming (range: 0-91) [mean $(S D)$ ] & $25.39(18.04)$ \\
\hline Desire for fame (range: $1-5)$ [mean $(S D)]$ & $2.37(1.01)$ \\
\hline NGSE self-efficacy (range: $1-5$ ) [mean $(S D)]$ & $3.56(0.81)$ \\
\hline
\end{tabular}

Note. CAS: Celebrity Attitude Scale; PIUQ-SF-6: Problematic Internet Use Questionnaire ShortForm; MDS-16: Maladaptive Daydreaming Scale; NGSE: New General Self-Efficacy Scale; $S D$ : standard deviation.

$\beta=0.10, p=.02)$, problematic Internet use $(B=0.44$, $\beta=0.19, p<.001)$, maladaptive daydreaming $(B=3.73$, $\beta=0.23, p<.001)$, and desire for fame $(B=1.79, \beta=0.22$, $p<.001)$ were significantly associated with this dimension of celebrity worship. Variables of Model 1 predicting the IntensePersonal dimension of celebrity worship explained $7 \%$ of the total variance, whereas Model 2 explained 15\%, and Model 3 explained $25 \%$ of the total variance. All models were significant $(p<.001)$. Similar to the associations found in relation to the Entertainment-Social subscale, gender $(B=2.69, \beta=0.16$, $p<.001)$, problematic Internet use $(B=0.30, \beta=0.16$, $p=.001)$, maladaptive daydreaming $(B=0.11, \quad \beta=0.28$, $p<.001)$, and desire for fame $(B=1.37, \beta=0.20, p<.001)$ were significant predictors of celebrity worship in Model 3. Variables of Model 1 predicting the Borderline-Pathological dimension of celebrity worship explained $4 \%$ of the total variance, whereas Model 2 reflected 17\%, and Model 3 explained $27 \%$ of the total variance. Again, all models were significant $(p<.001)$. In Model 3, problematic Internet use
( $B=0.20, \quad \beta=0.24, \quad p<.001)$, maladaptive daydreaming $(B=0.05, \beta=0.27, p<.001)$, and desire for fame $(B=0.58$, $\beta=0.20, p<.001)$ were significant predictors of this dimension of celebrity worship. Age had a significant negative association with celebrity worship only in Model 1 across all three analyses, and also in Model 2 in relation to the Borderline-Pathological dimension.]. In the final regression analysis (in which the total CAS was an outcome variable), the first model, comprising demographic characteristics $[F(436)=14.96, p<.001]$ explained $6 \%$ of the total variance, whereas the second model $[F(436)=22.46, p<.001]$, also including Internet use variables, accounted for $16 \%$ of the total variance. The third model $[F(436)=25.29$, $p<.001]$, to which psychological correlates were added, explained a notable proportion of the total variance of celebrity worship (28\%).

Gender was significantly associated with celebrity worship across the three regression models, indicating that females had higher scores than males on celebrity worship. 


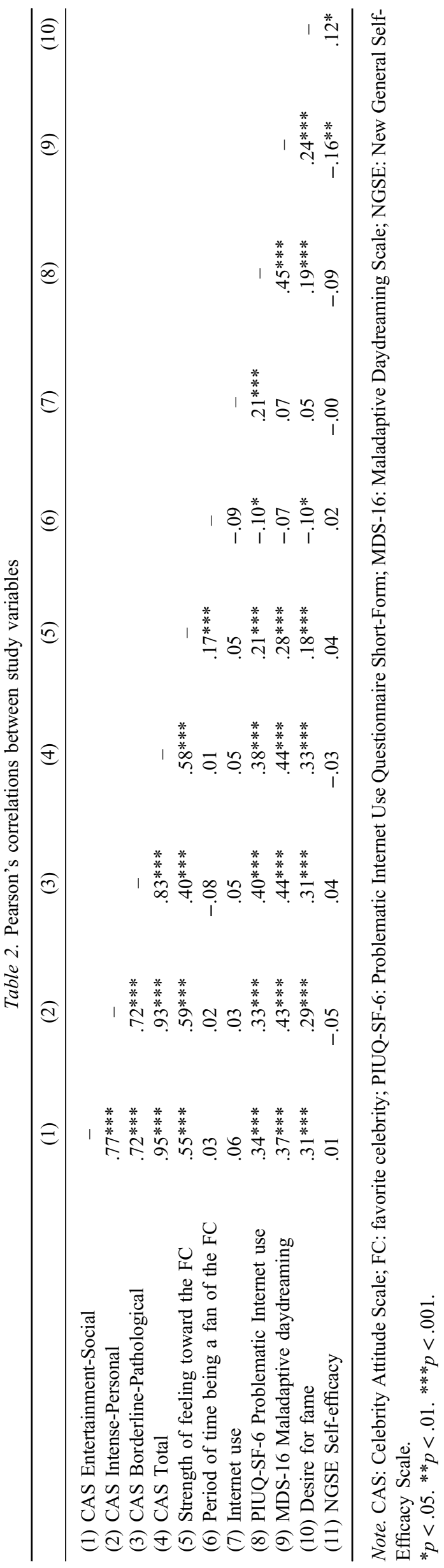

Age was negatively associated with celebrity worship in the first model $(B=-0.45, \beta=-0.20, p<.001)$, indicating that younger individuals had higher levels of celebrity worship than older individuals. However, this weak association between age and celebrity worship was not confirmed in the second and the third models.

With regard to Internet use, the frequency of usage was not associated with celebrity worship $(B=-0.37$, $\beta=-0.04, p=0.37$ ), but problematic use was found to be a significant predictor of celebrity worship $(B=0.93$, $\beta=0.20, p<.001)$. This result indicates that individuals scoring high on celebrity worship tend to report more mental health symptoms related to problematic Internet use.

In relation to psychological correlates, maladaptive daydreaming $(B=0.24, \beta=0.27, p<.001)$ and desire for fame $(B=3.73, \beta=0.23, p<.001)$ were significant predictors of celebrity worship. On the contrary, self-efficacy was unrelated to celebrity worship $(B=0.34, \beta=0.02, p=.69)$. This result suggests that higher levels of celebrity worship are associated with a tendency for maladaptive daydreaming and desire for fame.

Overall, the strongest predictors of celebrity worship were maladaptive daydreaming, desire for fame, and problematic Internet use.

\section{DISCUSSION AND CONCLUSIONS}

In the past two decades, there has been a growing research interest in individuals who are fascinated with celebrities (Sansone \& Sansone, 2014). The aim of this study was to contribute to a better understanding of this phenomenon by clarifying the links between Internet use habits and celebrity worship and by exploring its associations with maladaptive daydreaming, desire for fame, and self-efficacy. A positive relationship was found between celebrity worship, problematic Internet use, maladaptive daydreaming, and desire for fame. Furthermore, women were found to be at higher risk of becoming obsessed with their favorite celebrity than men. These results may enhance our understanding of the psychological difficulties related to celebrity worship.

In this study, $29.1 \%$ of participants yielded high scores on at least one subscale of the CAS, and $13.8 \%$ had high scores on at least one of the problematic dimensions (i.e., intense-personal and borderline-pathological) of celebrity worship. These prevalences are similar to those observed by Maltby and Day (2011) (i.e., 2.5\% and $8 \%$ scoring high on the Intense-Personal and the Borderline-Pathological dimensions) but relatively lower than those reported by Maltby et al. (2003) (i.e., 27\% scoring high on the two problematic dimensions). One possible explanation could be that the proportion of male participants was very high in the present sample, and some studies reported that females are more likely to become fascinated with celebrities than males (Reyes et al., 2016; Swami et al., 2011). However, due to the lack of cutoff points that are based on empirical findings, these prevalences should be interpreted with caution.

Similar to previous studies (Griffith et al., 2013; Sheridan et al., 2007; Swami et al., 2011), the most frequently chosen categories for participants' favorite celebrity were singers or musicians and actors/actresses. 
Table 3. Hierarchical linear regression models predicting celebrity worship $(N=437)$

\begin{tabular}{|c|c|c|c|c|}
\hline & \multicolumn{4}{|c|}{ Celebrity worship (CAS) } \\
\hline & $B[95 \% \mathrm{CI}]$ & $S E$ & $\beta$ & Adjusted $R^{2}$ \\
\hline Model I. Demographic characteristics & & & & .06 \\
\hline Gender $($ male $=1$, female $=2)$ & $6.62[2.95-10.29]$ & 1.87 & $0.17 * * *$ & \\
\hline Age & $-0.45[-0.65-0.24]$ & 0.10 & $-0.20 * * *$ & \\
\hline Model II. Internet use & & & & .16 \\
\hline Gender $($ male $=1$, female $=2)$ & $5.38[1.89-8.86]$ & 1.77 & $0.13 * *$ & \\
\hline Age & $-0.26[-0.46-0.06]$ & 0.10 & -0.12 & \\
\hline Internet use (hours per day) & $-0.44[-1.32-0.43]$ & 0.44 & -0.05 & \\
\hline PIUQ-SF-6 Problematic Internet use & $1.59[1.17-2.01]$ & 0.21 & $0.35^{* * *}$ & \\
\hline Model III. Psychological correlates & & & & .28 \\
\hline Gender $($ male $=1$, female $=2)$ & $4.92[1.64-8.19]$ & 1.67 & $0.12 * *$ & \\
\hline Age & $-0.08[-0.27-0.11]$ & 0.10 & -0.04 & \\
\hline Internet use (hours per day) & $-0.37[-1.18-0.44]$ & 0.41 & -0.04 & \\
\hline PIUQ-SF-6 Problematic Internet use & $0.93[0.50-1.36]$ & 0.22 & $0.20 * * *$ & \\
\hline MDS-16 Maladaptive daydreaming & $0.25[0.16-0.33]$ & 0.04 & $0.27 * * *$ & \\
\hline Desire for fame & $3.73[2.33-5.14]$ & 0.72 & $0.23 * * *$ & \\
\hline NGSE Self-efficacy & $0.34[-1.33-2.02]$ & 0.85 & 0.02 & \\
\hline
\end{tabular}

Note. CAS: Celebrity Attitude Scale; PIUQ-SF-6: Problematic Internet Use Questionnaire Short-Form; MDS-16: Maladaptive Daydreaming Scale; NGSE: New General Self-Efficacy Scale; SE: standard error; CI: confidence interval. $* * * p<.001 .{ }^{* *} p<0.01$.

With regard to demographic characteristics, women had a greater tendency of becoming absorbed in the personal lives of their favorite celebrity than men in this study. Most studies found no gender differences in celebrity worship (e.g., Maltby et al., 2003, 2004; McCutcheon, Scott, Aruguete, \& Parker, 2006), while some studies reported women scoring higher on the Entertainment-Social dimension of celebrity worship than men among Filipinos (Reyes et al., 2016; Vega et al., 2013) and in a Malay-speaking sample (Swami et al., 2011). One possible explanation for women scoring higher than men in these studies including this study could be cultural differences. However, the proportion of females in the present Hungarian sample is very limited. Therefore, further research is required to establish the role of cultural diversity in the varied levels of celebrity worship across gender.

In this study, age was only weakly associated with celebrity worship in the first model (demographic characteristics) of hierarchical regression, and unrelated to it when Internet use variables and psychological correlates were added to the model. Previous studies also found either no association between age and celebrity worship (e.g., Maltby et al., 2004, 2006) or a weak negative relationship (Maltby et al., 2003; Swami et al., 2011).

When investigating Internet use habits and psychological correlates, two hypotheses were formulated. The results of this study revealed a positive relationship between problematic Internet use and celebrity worship, whereas the amount of time spent online was not associated with celebrity worship. Therefore, the first hypothesis was supported. This finding indicates that those with higher levels of celebrity worship experience more symptoms related to problematic Internet use; however, the amount of time spent online is unrelated to the extent of admiration of celebrities. This result corroborates previous findings that demonstrated problematic Internet use is more strongly associated with comorbid mental health problems and maladaptive behaviors that could interfere with the person's life (e.g., addictive level of celebrity worship) than the time spent online (Caplan, 2002; Davis et al., 2002; Demetrovics et al., 2008).

In relation to psychological correlates, a positive relationship was found between celebrity worship, maladaptive daydreaming, and desire for fame. However, no association was found between celebrity worship and self-efficacy. Therefore, the second hypothesis was only partially supported.

Unsurprisingly, a positive relationship was found between celebrity worship and maladaptive daydreaming, indicating that individuals with an extensive fantasy activity are more likely to be obsessed with celebrities. These psychological constructs have several similarities; for instance, both had a positive association with fantasy proneness in previous studies (Bigelsen et al., 2016; Maltby et al., 2006; McCutcheon, Aruguete, McCarley, et al., 2016), and both could have a detrimental effect on the person's educational, work-related performance, and interpersonal relationships (Maltby et al., 2003, 2004; Somer, 2002).

Furthermore, a positive relationship was found between celebrity worship and desire for fame, indicating that those who find celebrities' lifestyles appealing to them and wish to be recognized have a higher tendency to worship celebrities. Reeves et al. (2013) found a similar association among these two phenomena. The absorption-addiction model by McCutcheon et al. (2002) could possibly provide an explanation for this association. In more details, this model proposes that some individuals with a loosely integrated identity structure are more likely to become obsessed with a celebrity as a result of an attempt to strengthen their identity structure and gain a sense of fulfillment. However, when an addictive component is incorporated in this process, the dynamics of motivations can lead to extreme behaviors in 
order to maintain satisfaction with the person's favorite celebrity. According to this, compulsive levels of celebrity worship can possibly become a compensatory behavior for those with a high desire for fame through the identification with a celebrity who possesses all the characteristics that are desirable for the individual (e.g., appreciated and attractive).

Finally, no association was found between celebrity worship and self-efficacy in this study. Gardner and Pierce (1998) pointed out that self-esteem and self-efficacy are closely related constructs. For instance, individuals who perceive themselves as competent and worthy are more likely to achieve their goals in their personal performance (Gardner \& Pierce, 1998). Self-esteem was found to be positively related to the two problematic dimensions of celebrity worship (i.e., intense-personal and borderlinepathological) in a United Kingdom sample (Ashe et al., 2005), and a similar association was observed in another study by North, Sheridan, Maltby, and Gillett (2007) in which the Intense-Personal dimension was positively associated with self-esteem in an European and North American sample. These findings indicate that addictive levels of celebrity worship are rather associated with narcissism and high self-esteem (Ashe et al., 2005) than a sense of incompetence and insignificance that might be assumed to correlate with celebrity worship as it implies a loss of control over the person's admiration toward a celebrity. However, it should also be noted that a considerable proportion of individuals may not perceive their compulsive feelings and behaviors as harmful, and these individuals may not be aware of the severity of consequences of their obsession as was proposed by Wang, $\mathrm{Wu}$, and Lau (2016) in relation to problematic Internet use. Therefore, they might maintain a perception of competence and self-efficacy in spite of the harms their obsession causes in several life aspects.

This study is not without limitations. First, it should be noted that data analysis was conducted on a nonrepresentative sample of Hungarian adolescents and adults. Therefore, findings of this study may not be generalizable to the whole Hungarian population. Second, inferences cannot be established upon these data due to the cross-sectional design of the study. Third, the proportion of female participants is very limited in this study. Therefore, future studies should use larger samples to find further support for the gender differences in celebrity worship that were demonstrated in this study. It should also be noted that the calculation of prevalence of individuals exhibiting high levels of celebrity worship in this study is based upon theoretical midpoints (Maltby et al., 2003), not on empirically established cutoff points, and hence should be interpreted with caution. Another limitation could be that the incentive offered for participants could possibly increase the likelihood of multiple completion of the questionnaire in order to secure higher chance for winning, which can lead to distortion in the results. Furthermore, the final regression model that included all study-relevant variables explained only one quarter of the total variance, indicating that other variables should be considered in future research as potential correlates of celebrity worship that may explain a larger proportion of this construct (e.g., social factors such as the quality of interpersonal relationships, social competence, fan activities, and affiliation to fan communities). Future research should also investigate Internet-related activities in more details that might be associated with celebrity worship (e.g., social networking sites use).

Despite the limitations, this study offered a more nuanced picture of the association of celebrity worship with problematic and non-problematic Internet use, maladaptive daydreaming, desire for fame, and self-efficacy. By broadening the scope of psychological difficulties that should be considered in relation to celebrity worship, these findings may contribute to a more comprehensive understanding of the nature and dynamics of this phenomenon.

Funding sources: This study was supported by the Hungarian National Research, Development and Innovation Office (grant numbers: K111938 and KKP126835). ÁZ was supported by the ÚNKP-17-3 New National Excellence Program of the Ministry of Human Capacities.

Authors' contribution: ÁZ substantially contributed to the study concept and design, data gathering, data analyses, interpretation of the results, and the writing of the manuscript. LEM substantially contributed to the interpretation of the results, study concept, and the revision of the manuscript. ZD substantially contributed to the study concept and study supervision. All authors had full access to all data in the study and take responsibility for the integrity of the data and the accuracy of the data analysis.

Conflict of interest: The authors declared no conflict of interest.

\section{REFERENCES}

Anderson, E. L., Steen, E., \& Stavropoulos, V. (2017). Internet use and problematic Internet use: A systematic review of longitudinal research trends in adolescence and emergent adulthood. International Journal of Adolescence and Youth, 22(4), 430-454. doi:10.1080/02673843.2016.1227716

Ashe, D. D., Maltby, J., \& McCutcheon, L. E. (2005). Are celebrity-worshippers more prone to narcissism? A brief report. North American Journal of Psychology, 7(2), 239-246.

Bai, Y. M., Lin, C. C., \& Chen, J. Y. (2001). Internet addiction disorder among clients of a virtual clinic. Psychiatric Services, 52(10), 1397-1397. doi:10.1176/appi.ps.52.10.1397

Beaton, D. E., Bombardier, C., Guillemin, F., \& Ferraz, M. B. (2000). Guidelines for the process of cross-cultural adaptation of self-report measures. Spine, 25(24), 3186-3191. doi:10. 1097/00007632-200012150-00014

Bigelsen, J., Lehrfeld, J. M., Jopp, D. S., \& Somer, E. (2016). Maladaptive daydreaming: Evidence for an under-researched mental health disorder. Consciousness and Cognition, 42, 254-266. doi:10.1016/j.concog.2016.03.017

Brunborg, G. S., Mentzoni, R. A., Melkevik, O. R., Torsheim, T., Samdal, O., Hetland, J., Andreassen, C. S., \& Palleson, S. (2013). Gaming addiction, gaming engagement, and psychological health complaints among Norwegian adolescents. Media Psychology, 16(1), 115-128. doi:10.1080/15213269. 2012.756374 
Caplan, S. E. (2002). Problematic Internet use and psychosocial well-being: Development of a theory-based cognitive-behavioral measurement instrument. Computers in Human Behavior, 18(5), 553-575. doi:10.1016/S0747-5632(02)00004-3

Chen, G., Gully, S. M., \& Eden, D. (2001). Validation of a new general self-efficacy scale. Organizational Research Methods, 4(1), 62-83. doi:10.1177/109442810141004

Davis, R. A. (2001). A cognitive-behavioral model of pathological Internet use. Computers in Human Behavior, 17(2), 187-195. doi:10.1016/S0747-5632(00)00041-8

Davis, R. A., Flett, G. L., \& Besser, A. (2002). Validation of a new scale for measuring problematic Internet use: Implications for pre-employment screening. CyberPsychology \& Behavior, 5(4), 331-345. doi:10.1089/109493102760275581

Demetrovics, Z., \& Király, O. (2016). Commentary on Baggio et al. (2016): Internet/gaming addiction is more than heavy use over time. Addiction, 111(3), 523-524. doi:10.1111/add.13244

Demetrovics, Z., Király, O., Koronczai, B., Griffiths, M. D., Nagygyörgy, K., Elekes, Z., Tamás, D., Kun, B., Kökönyei, G., \& Urbán, R. (2016). Psychometric properties of the Problematic Internet Use Questionnaire Short-Form (PIUQ-SF-6) in a nationally representative sample of adolescents. PLoS One, 11(8), e0159409. doi:10.1371/journal.pone.0159409

Demetrovics, Z., Szeredi, B., \& Rózsa, S. (2008). The three-factor model of Internet addiction: The development of the Problematic Internet Use Questionnaire. Behavior Research Methods, 40(2), 563-574. doi:10.3758/BRM.40.2.563

Gardner, D. G., \& Pierce, J. L. (1998). Self-esteem and selfefficacy within the organizational context: An empirical examination. Group \& Organization Management, 23(1), 48-70. doi: $10.1177 / 1059601198231004$

Giles, D. C., \& Maltby, J. (2004). The role of media figures in adolescent development: Relations between autonomy, attachment, and interest in celebrities. Personality and Individual Differences, 36(4), 813-822. doi:10.1016/S0191-8869(03) 00154-5

Gountas, J., Gountas, S., Reeves, R. A., \& Moran, L. (2012). Desire for fame: Scale development and association with personal goals and aspirations. Psychology \& Marketing, 29(9), 680-689. doi:10.1002/mar.20554

Griffith, J., Aruguete, M., Edman, J., Green, T., \& McCutcheon, L. (2013). The temporal stability of the tendency to worship celebrities. SAGE Open, 3(2), 215824401349421. doi:10. $1177 / 2158244013494221$

Griffiths, M. (2000). Does Internet and computer "addiction” exist? Some case study evidence. CyberPsychology \& Behavior, 3(2), 211-218. doi:10.1089/109493100316067

Király, O., Griffiths, M. D., Urbán, R., Farkas, J., Kökönyei, G., Elekes, Z., Tamás, D., \& Demetrovics, Z. (2014). Problematic Internet use and problematic online gaming are not the same: Findings from a large nationally representative adolescent sample. Cyberpsychology, Behavior, and Social Networking, 17(12), 749-754. doi:10.1089/cyber.2014.0475

Király, O., Tóth, D., Urbán, R., Demetrovics, Z., \& Maraz, A. (2017). Intense video gaming is not essentially problematic. Psychology of Addictive Behaviors, 31(7), 807-817. doi:10. 1037/adb0000316

Lu, H. Y. (2008). Sensation-seeking, Internet dependency, and online interpersonal deception. CyberPsychology \& Behavior, 11(2), 227-231. doi:10.1089/cpb.2007.0053
Maltby, J., \& Day, L. (2011). Celebrity worship and incidence of elective cosmetic surgery: Evidence of a link among young adults. Journal of Adolescent Health, 49(5), 483-489. doi:10.1016/j.jadohealth.2010.12.014

Maltby, J., Day, L., McCutcheon, L. E., Gillett, R., Houran, J., \& Ashe, D. D. (2004). Personality and coping: A context for examining celebrity worship and mental health. British Journal of Psychology, 95(4), 411-428. doi:10.1348/00071260 42369794

Maltby, J., Day, L., McCutcheon, L. E., Houran, J., \& Ashe, D. (2006). Extreme celebrity worship, fantasy proneness and dissociation: Developing the measurement and understanding of celebrity worship within a clinical personality context. Personality and Individual Differences, 40(2), 273-283. doi:10.1016/j.paid.2005.07.004

Maltby, J., Houran, J., \& McCutcheon, L. E. (2003). A clinical interpretation of attitudes and behaviors associated with celebrity worship. The Journal of Nervous and Mental Disease, 191(1), 25-29. doi:10.1097/00005053-200301000-00005

Maltby, J., McCutcheon, L. E., Ashe, D. D., \& Houran, J. (2001). The self-reported psychological well-being of celebrity worshippers. North American Journal of Psychology, 3(3), 441-452.

Martin, M. M., McCutcheon, L. E., \& Cayanus, J. (2015). Celebrity worship and its relationship to television-watching motives: A brief report. North American Journal of Psychology, 17(2), 213-220.

McCutcheon, L. E., Aruguete, M. S., Griffith, J. D., \& Haight, E. (2012). Cognitive ability and celebrity worship revisited. North American Journal of Psychology, 14(2), 383-392.

McCutcheon, L. E., Aruguete, M., McCarley, N. G., \& Jenkins, W. J. (2016). Further validation of an indirect measure of celebrity stalking. Journal of Studies in Social Sciences, 14(1), 75-91.

McCutcheon, L. E., Aruguete, M. S., Jenkins, W., McCarley, N., \& Yockey, R. (2016). An investigation of demographic correlates of the Celebrity Attitude Scale. Interpersona, 10(2), 161-170. doi:10.5964/ijpr.v10i2.218

McCutcheon, L. E., Gillen, M. M., Browne, B. L., Murtagh, M. P., \& Collisson, B. (2016). Intimate relationships and attitudes toward celebrities. Interpersona, 10(1), 77-89. doi:10.5964/ ijpr.v10i1.208

McCutcheon, L. E., Lange, R., \& Houran, J. (2002). Conceptualization and measurement of celebrity worship. British Journal of Psychology, 93(1), 67-87. doi:10.1348/000712602162454

McCutcheon, L. E., Maltby, J., Houran, J., \& Ashe, D. (2004). Celebrity worshippers: Inside the minds of stargazers. Baltimore, MD: Publish America.

McCutcheon, L. E., Scott, V. B., Jr., Aruguete, M. S., \& Parker, J. (2006). Exploring the link between attachment and the inclination to obsess about or stalk celebrities. North American Journal of Psychology, 8(2), 289-300.

Merckelbach, H., Horselenberg, R., \& Muris, P. (2001). The Creative Experiences Questionnaire (CEQ): A brief self-report measure of fantasy proneness. Personality and Individual Differences, 31(6), 987-995. doi:10.1016/S0191-8869(00) 00201-4

Niemz, K., Griffiths, M., \& Banyard, P. (2005). Prevalence of pathological Internet use among university students and correlations with self-esteem, the General Health Questionnaire 
(GHQ), and disinhibition. CyberPsychology \& Behavior, 8(6), 562-570. doi:10.1089/cpb.2005.8.562

North, A. C., Sheridan, L., Maltby, J., \& Gillett, R. (2007). Attributional style, self-esteem, and celebrity worship. Media Psychology, 9(2), 291-308. doi:10.1080/15213260701285975

O'brien, R. M. (2007). A caution regarding rules of thumb for variance inflation factors. Quality \& Quantity, 41(5), 673-690. doi:10.1007/s11135-006-9018-6

Reeves, R., Lemons, C., Clements, A., Gountas, J., \& Gountas, S. (2013). Celebrity worship, desire for fame, materialism, and social media use. Paper presented at the Annual Meeting of the Southeastern Psychological Association, Atlanta, GA.

Reyes, M. E. S., Santiago, A. G. F., Domingo, A. J. A., Lichingyao, E. N., \& Onglengco, M. N. M. (2016). Fandom: Exploring the relationship between mental health and celebrity worship among Filipinos. North American Journal of Psychology, 18(2), 307-316.

Sansone, R. A., \& Sansone, L. A. (2014). "I'm Your Number One Fan" - A clinical look at celebrity worship. Innovations in Clinical Neuroscience, 11(1-2), 39-43.

Shapira, N. A., Goldsmith, T. D., Keck, P. E., Jr., Khosla, U. M., \& McElroy, S. L. (2000). Psychiatric features of individuals with problematic Internet use. Journal of Affective Disorders, 57(1-3), 267-272. doi:10.1016/S0165-0327(99) 00107-X

Sheridan, L., North, A., Maltby, J., \& Gillett, R. (2007). Celebrity worship, addiction and criminality. Psychology, Crime \& Law, 13(6), 559-571. doi:10.1080/10683160601160653

Skoric, M. M., Teo, L. L. C., \& Neo, R. L. (2009). Children and video games: Addiction, engagement, and scholastic achievement. CyberPsychology \& Behavior, 12(5), 567-572. doi:10. 1089/cpb.2009.0079

Somer, E. (2002). Maladaptive daydreaming: A qualitative inquiry. Journal of Contemporary Psychotherapy, 32(2-3), 197-212. doi:10.1023/A:1020597026919

Somer, E., Soffer-Dudek, N., Ross, C. A., \& Halpern, N. (2017). Maladaptive daydreaming: Proposed diagnostic criteria and their assessment with a structured clinical interview.
Psychology of Consciousness: Theory, Research, and Practice, 4(2), 176-189. doi:10.1037/cns0000114

Stajkovic, A. D., \& Luthans, F. (1998). Self-efficacy and workrelated performance: A meta-analysis. Psychological Bulletin, 124(2), 240-261. doi:10.1037/0033-2909.124.2.240

Stever, G. S. (2011). Celebrity worship: Critiquing a construct. Journal of Applied Social Psychology, 41(6), 1356-1370. doi:10.1111/j.1559-1816.2011.00765.X

Sun, S., Rubin, A. M., \& Haridakis, P. M. (2008). The role of motivation and media involvement in explaining Internet dependency. Journal of Broadcasting \& Electronic Media, 52(3), 408-431. doi:10.1080/08838150802205595

Swami, V., Chamorro-Premuzic, T., Mastor, K., Hazwani Siran, F., Said, M. M. M., Jaafar, J., Sinniah, D., \& Pillai, S. K. (2011). Celebrity worship among university students in Malaysia: A methodological contribution to the Celebrity Attitude Scale. European Psychologist, 16(4), 334-342. doi:10.1027/1016-9040/a000029

Swami, V., Taylor, R., \& Carvalho, C. (2009). Acceptance of cosmetic surgery and celebrity worship: Evidence of associations among female undergraduates. Personality and Individual Differences, 47(8), 869-872. doi:10.1016/j.paid.2009.07.006

Vega, C. B., Magpantay, J., Zapanta, J., Tolentino, R., Varona, A. A., Tengco-Pacquing, C., \& McCutcheon, L. E. (2013). A brief report on Celebrity Attitude Scale data collected in the Philippines. North American Journal of Psychology, 15(1), 213-214.

Wang, Y., Wu, A. M., \& Lau, J. T. (2016). The health belief model and number of peers with Internet addiction as inter-related factors of Internet addiction among secondary school students in Hong Kong. BMC Public Health, 16(1), 272. doi:10.1186/ s12889-016-2947-7

Yellowlees, P. M., \& Marks, S. (2007). Problematic Internet use or Internet addiction? Computers in Human Behavior, 23(3), 1447-1453. doi:10.1016/j.chb.2005.05.004

Young, K. S. (1998). Internet addiction: The emergence of a new clinical disorder. CyberPsychology \& Behavior, 1(3), 237-244. doi:10.1089/cpb.1998.1.237 